\title{
Direction and Motivation of Prehospital Personnel to Do Research: How to Do It Better
}

\author{
Captain Wesley J. Warnke, EMT-P, ${ }^{1}$ Marni J. Bonnin, MD, FACEP ${ }^{2}$
}

The Emergency Medical Services Division of the Houston Fire Department was started in 1971 and operated independent of physician input until 1984, when the first medical director was hired. The first prehospital research project was begun in 1986. The medical director, Dr. Paul Pepe, spent the intervening two years learning and improving on the system before beginning any research projects. He tested skills, established protocols for better patient care, and generally upgraded the system. This required an extensive amount of work on the part of the medical director, not only in the office, but also on the streets of the city at all hours of the day and night. Not only did the medical director learn about his system and his personnel, but the EMS personnel learned about their medical director. This is a basis for establishing credibility as a leader.

In order to be a credible leader, the medical director must be perceived as a competent, enthusiastic, empathetic, inspirational, and sometimes aggressive person with a progressive attitude regarding good patient care. This can be achieved by a combination of time in the field, in the office, and in the classroom. The medical director should stay in touch with his/ her personnel, keep communication lines open in both directions, and be aware of important personal characteristics and crises which may be influencing the EMT's behaviors and decisions. In an ALS or tiered system, interest must be shown in all levels of responses, including basic "sick calls" and BLS level "routine" runs.

One behavior which the Medical Director should avoid is frequent appearances on "VIP" or high-profile media scenes, which gives the EMS personnel the impression of self-glorification or self-importance. Credit always should be given to the medic in the streets if at all possible. This builds a good relationship between the medical director and the field personnel which can influence personnel response to requests for assistance with field research.

Why do EMS personnel need to be motivated to do research? It must be realized that most prehospital research projects require EMS personnel to:

1) Increase their workload and the number of steps taken during emergent patient care;
2) Augment their mental workload by remembering inclusion and exclusion criteria, protocols, and new procedures;

3) Increase documentation and paper work load;

4) Increase their responsibility for proper protocol execution; and

5) Break from their traditional protocols, procedures, and practices.

So why should EMS personnel do research? The advancement of medical knowledge and science is not necessarily as important to the average EMT or paramedic as it is to the physician-researcher. However, the goal of improving patient care in some tangible way is more likely to motivate EMS personnel than attempting to answer some esoteric research question. Also, in a paramilitary EMS system, as many of them are, if your objective as a leader is to answer this research question, then our objective as your team is to assist you. For this reason, EMS research is done more easily in systems with paramilitary structure.

Also, EMS research is done more easily in systems with EMS supervisors. The supervisor provides more constant contact with the field personnel, and can give feedback to the field personnel and to the Medical Director. Questions that arise either can be answered by the supervisor or relayed back to the Medical Director, and a supervisors' presence on the scene can help assure adherence to protocols.

It is essential that these EMS supervisors have a positive image of the Medical Director and of the research project, as the supervisors' views will be passed down to their personnel. The Medical Director must pay close attention to the supervisors and cultivate these positive attitudes in order for prehospital research to be a success in his/her system.

The field personnel and supervisors are valuable team members, not just "gophers." The EMT should be made to feel a part of the team, and must have a clear understanding of the importance of the research project, not only to the Medical Director, but also to medical science and patient care. If the field personnel believe that the research merely is to further the Medical Director's career and to build up his/her ego and resume, the project is doomed. It is difficult

1. President, Houston Professional Firefighters Association Paramedic Supervisor, Houston Fire Department EMS Division

2. Assistant Professor of Surgery/Emergency Medicine, University of Texas Medical School at Houston

Presented to the Annual Meeting of the National Association of EMS Physicians, Houston, Texas, June, 1990 


\section{"It is too late to plan a response once a disaster occurs."}

JF Waeckerle, MD, FACEP

New England Journal of Medicine 1991; 324:820

\section{ACEP announces}

\section{Disasters: Medical Planning and Management April 4-5, 1992 - Chicago, Illinois}

\section{Become a stronger leader in disaster planning. Your role is critical!}

\section{Learn the Common Principles of Disaster Management:}

- Triage is crucial.

- A management and command structure must be in place.

- Personnel roles must be clearly defined.

- Good communication is essential.

- Adequate supplies and equipment must be available.

- Cooperation between various agencies must be established.

Disasters: Medical Planning and Management

April 4-5, 1992 - Chicago, Illinois

FOR INSTANT REGISTRATION, CALL TOLL-FREE (800) 798-1822

\section{Registration Fees:}

ACEP member

Non-member physician

Nurse*

Hospital Administrator

EMS Administrator

*Nurses only.

License

SS\#

Name

MemberID\#

Title

Address

\section{City/State/Zip+4}

Telephone

\section{Payment Information}

My check for $\$$

(Payable to ACEP).

Please charge my

Card\#

Exp. date

MC Bank\#

Signature

Mail to: ACEP Registrar, P.O.Box 619911

Dallas, TX 75261-9911

24-Hour FAX: (214) 580-2816.

Written cancellations can be accepted until March 4, 1992 Cancella

\section{Who Should Attend:}

- ED Directors

- Emergency Physicians

- ED Nurses and Nurse Supervisors

- Hospital Administrators

- EMS Administrators

- Ambulance Service Supervisors

- Other Key Health Care Providers

Involved in Disaster Planning/Response

\section{Hotel Information:}

The new Sheraton Chicago Hotel and Towers - (312) 464-1000

\section{Earn 16.5 CME} Credit Hours!

\section{0\% Money-Back Guarantee!}

If you are not satisfied with any ACEP course, just notify us in writing within 30 days of attending the course and we will credit or refund your money.

\section{Expert Faculty!}

Robert R. Zelenak, DO, FACEP.

Course coordinator.

Richard V. Aghababian, MD, FACEP

Andrew I. Bern, MD, FACEP

Richard A. Craven, MD, FACEP

Ralph B. Leonard, PhD, MD, FACEP

Paul B. Roth, MD, FAAFP, FACEP

Henry J. Siegelson, MD, FACEP

Joseph F. Waeckerle, MD, FACEP

Case Studies!

Q \& A Sessions!

Triage Simulation Exercise 


\section{Concise. Current. Reliable.}

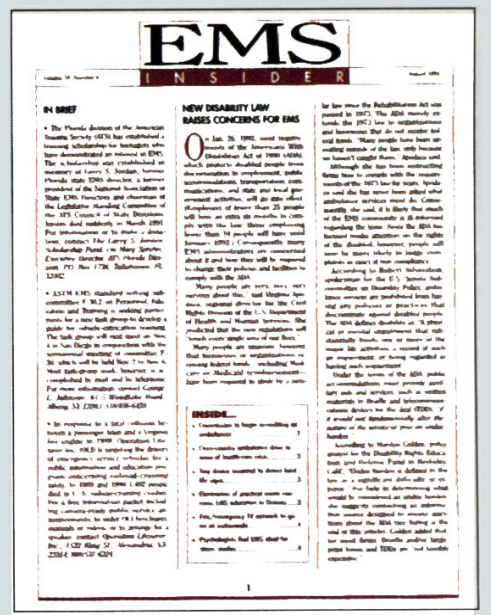

\section{The monthly must-have newsletter for emergency medical professionals}

Providing the industry's most up-to-date and incisive reporting on:

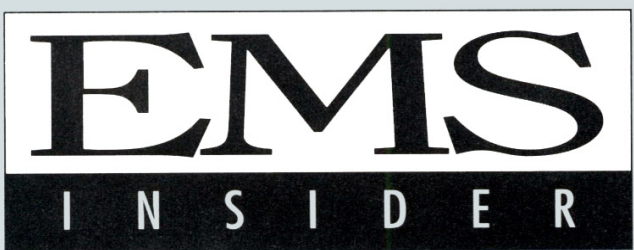

Published by Jems Communications
- Legislative issues-national,

state and local

- Grants and funding news

- New drugs and treatments

- Litigation

- New products

- Current controversies

The EMS INSIDER is your source for coverage of critical issues-issues that are evolving and dynamic, and that will dramatically affect the EMS industry. The staff of the EMS INSIDER reviews hundreds of reports and documents each month and interviews dozens of people to bring you the fastest-breaking news on a wide range of topics. We carefully check all information, and only print the most vital stories with the most immediate, universal use.

It's hard for busy managers to find time to read everything they'd like. The EMS INSIDER does it for you-then presents the information you need to keep up-to-date and informed.

You'll find articles about techniques that work like magic and innovations that went wrong. Read about legislation that can mean big benefits for ambulance services-and lawsuits that have put others out of business. When a controversy is brewing, we'll have a complete report. And as new drugs are successfully tested, we'll let you know when to expect to have access to them.

The information you get in the EMS INSIDER is often unavailable anywhere else. The stories we research so aggressively today are the stories that will shape EMS tomorrow. We think you deserve to know.

It's up to you. The news and issues of EMS are developing even as you read this.

Why wait? It's easy and inexpensive to get your own subscription started now. With the EMS INSIDER you'll get the best information as soon as it's available.

\section{To order, use the card beside this ad. Don't wait! If card is missing, call 1-800-266-JEMS. Outside the U.S. 619-431-9797.}




\section{Subscription and Business Information for the Readers of \\ Prehospital and Disaster Medicine}

\section{SUBSCRIPTION PRICES}

One-year

(4 issues)

Institutional $\ldots \ldots \ldots \ldots \ldots \ldots \ldots \ldots \$ 78 \ldots \ldots \ldots 148$

Individual $\ldots \ldots \ldots \ldots \ldots \ldots \ldots \ldots \ldots 48 \ldots \ldots \ldots 8$

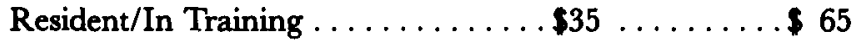

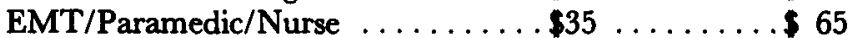

Note: "Institutional Subscribers"' are defined as multiple reader subscribers and include public and private libraries, schools, hospitals and clinics; city, county, state, provincial and national government bureaus and departments; and all commercial and private institutions and organizations.

Individual subscriptions and all student-rate subscriptions must be in the name of, billed to, and paid by individuals. All studentrate requests must indicate training status and name of institution.

Send U.S. subscription orders to: Jems Publishing Company, PDM, P.O. Box 2789, Carlsbad, CA 92018; 619/431-9797; FAX: $619 / 431-8176$.

\section{INTERNATIONAL SUBSCRIPTIONS}

International subscription orders should be directed to : Jems Publishing Company, P.O. Box 2789, Carlsbad, CA 92018; telephone: 619/431-9797; FAX: 619/431-8176. Canadian subscribers add $\$ 10$ per year for postage and handling. Please include payment in U.S. funds. All other international subscribers add $\$ 20$ per year.

\section{CHANGE OF ADDRESS \& MISSING ISSUES}

Please let your subscription representative know as soon as possible when you plan to move. We need four to six weeks advance notice for uninterrupted service. Send us your 1) current mailing label (with old address), 2) your new address and 3) effective date of change. If you did not receive an issue, let us know within three months of cover date.

If you have other questions about your subscription, please address them to: Customer Service, Jems Publishing Company, P.O. Box 2789, Carlsbad, CA 92018.

\section{EDITORIAL INFORMATION}

Please address all manuscript and editorial inquiries and comments to: Marvin L. Birnbaum, Editor, Prehospital and Disaster Medicine, 1552 University Ave., Rm. 434, Madison, WI 53705; 608/263-2069 or 608/263-7094; FAX: 608/263-2069.

\section{ASSOCIATION CONTACTS}

National Association of Emergency Medical Services Physicians, Executive and National Resource Center, 230 McKee Place, Suite 500, Pittsburgh, PA 15213; 1-800/228-3677.

World Association for Emergency and Disaster Medicine, Dr. Peter J.F. Baskett, President, Dept. of Anaesthesia, Frenchay Hospital, Bristol BS 16 1LE, United Kingdom.

Acute Care Foundation, P.O. Box 90193, Lakeland, FL, 33804 0193; 813/539-7352.

National Association for State EMS Directors, 1947 Camino Vida Roble, Suite 202, Carlsbad, CA 92008; 619/431-7054.

\section{Missing back issues of PDM? \\ Complete your \\ Prehospital and Emergency Medicine Journal Library}

Receive a FREE Listing of past issues simply by completing this form and mailing to:

\section{Jems Communications, P.O. Box 2789 Carlsbad, CA 92018}

Yes, please send me a contents listing of all past issues of Prehospital and Disaster Medicine, and the Journal of the World Association for Emergency and Disaster Medicine.

Name (please print)

Organization

Address

City State Zip Phone ( ) 
PREHOSPITAL and DISASTER MEDICINE

A quarterly

peer-reviewed

scientific journal

for physicians,

nurses, paramedics,

instructors,

administrators

and researchers

\section{The official journal of:}

The National

Association of EMS

Physicians

The World Association for Emergency and Disaster Medicine

In Association with the Acute Care Foundation and the National Association of State EMS Directors

\section{MMS INSIDER}

The EMS Insider is the monthly newsletter that provides the latest-breaking news about EMS legislation, regulations, medical developments and funding. It keeps EMS decision makers abreast of the latest developments, innovations and controversies in prehospital care.

Get EMS news while it's still NEW!

Subscribe today and save.

12 issues regularly $\$ 49.00$

SPECIAL

INTRODUCTORY OFFER $\ldots \ldots . \$ 29.50$

\section{Yes! Please enter my subscription to PDM for:}

1 year (4 issues): $\square$ \$78 Institutional $\square$ \$48 Individual $\square$ \$35 Resident/In Training $\square$ \$35 EMT, Paramedic, RN 2 years (8 issues): $\square$ \$148 Institutional $\square$ \$88 Individual $\square$ \$65 Resident/In Training $\square$ \$65 EMT, Paramedic, RN

NOTE: "Institutional" defines multiple reader subscriptions, including libraries, hospitals, government agencies, and all private organizations.

Individual subscriptions must be paid by individuals.

This offer expires 03/31/92

Name/Institution

Address

City

$\square$ Bill me

State*

Zip

$\square$ Payment Enclosed Card \#

* Califormia residents must

add $8.25 \%$ sales tax. For

Canadian subsonipt

$\$ 10$.

Occupation:

Physician

Nurse

EMT. Paramedic

Administrater/Supv./Purch. Agent

Disaster/Civil Defense Planner

Signature

Date

31XZF4

$\square$ Other

Make checks payable to PDM, P.O. Box 2789, Carlsbad, CA 92018

Primary Specialty (if Physician)

Employment Location:

$\square$ Emergency Medicine

$\square$ Hospital
$\square$ Fire Department

$\square$ Fire Department

$\square$ Regional/State/Federal Agenc

Critical Care

$\square$ Traumatology

$\square$ Prehospital Medical Director

Cardiology

$\square$ Industry

$\square$ Other

Please Specify)

Please Specits)

\section{Prehospital and Disaster Medicine}

Yes! Please enter my subscription to PDM for:

1 year (4 issues): $\square$ \$78 Institutional $\square$ \$48 Individual $\square$ \$35 Resident/In Training $\square$ \$35 EMT, Paramedic, RN 2 years (8 issues): $\square$ \$148 Institutional $\square$ \$88 Individual $\square$ \$65 Resident/In Training $\square$ \$65 EMT, Paramedic, RN

NOTE: "Institutional" defines multiple reader subscriptions, including libraries, hospitals, government agencies, and all private organizations.

Individual subscriptions must be paid by individuals.

This offer expires 03/31/92

Name/Institution

Address

City

State *

Zip

$\square$ Bill me $\square$ Charge my: $\square$ VISA $\square$ MasterCard Exp. Date

$\square$ Payment Enclosed Card \#

*Califormia residents must

add $8.25 \%$ sales tax. For

Signature

Date

Canadian subscriptions, add Make checks payable to PDM, P.O. Box 2789, Carlsbad, CA 92018

$31 X Z F 4$

Occupation:

$\square$ Phusician

$\square$ Nurse

$\square$ EMT, Paramedic

Administrator/Supv./Purch. Agen

Disaster/Civil Defense Planner

$\square$ Other_ (Please Specify)

Employment Location:

$\square$ Hospital

$\square$ Fire Department

$\square$ Ambulance Service

$\square$ Regional/State/Federal Agency

$\square$ Industry

$\square$ Other

(Please Specify)

Primary Specialty (if Physician)

$\square$ Emergency Medicine

$\square$ Critical Care

$\square$ Traumatology

$\square$ Prehospital Medical Director

$\square$ Cardiology

$\square$ Other

(Please Specifv)
Yes, I need the kind of timely information that only the EMS INSIDER provides. And by ordering now I'll take advantage of the introductory price-just $\$ 29.50$ for 12 monthly issues. (Regular price is $\$ 49.00$ )

Print Name

Title Organization

Address

$\overline{\text { City }}$

a BILL ME

EMPLOYER/AFFILIATION

I. Hospital

2. Private Ambulance

0 3. Fire Dept./Rescue Squad

4. Third Serv./Mun. Agency

0 5 . Industrial/Commerical

6. Other

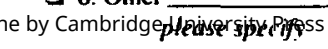

Stale *

Zip

【 PAYMENT ENCLOSED

OCCUPATION/POSITION

U A. Physician

G B. Nurse/Inst./Coord.

$\checkmark$ C. Administrator/Supervisor

D D. Paramed./EMT - I/EMT-D

O E. EMIT (Basic, IsI Resp.)

0 F. Other

plcase specif
Offer expires 06/30/92

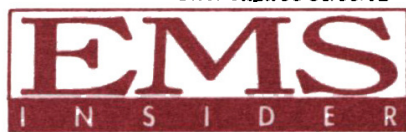

RISK FREE SUBSCRIPTION!

If you are unhappy with the EMS INSIDER, you may cancel your subscription at any time and receive a refund on the remaining issues.

C CHARGE MY

U VISA U MasterCard Exp. Dale

Card \#

Signature

"California residents must add $\bar{B} .25 \%$ sales tax: total is \$31.93. Canada-please add $\$ 6$ per year for postage. All other foreign-please add $\$ 10$ per year for surface mail postage; add $\$ 20$ per year for air mail postage. Please allow postage; add $\$ 20$ per year for air mail postage. Please allow
$6-8$ weeks for delivery of first issue. 


\section{BUSINESS REPLY MAIL \\ FIRST CLASS PERMIT NO.759 \\ CARLSBAD, CA}

POSTAGE WILL BE PAID BY ADDRESSEE

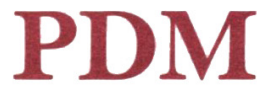

P.O. Box 2789

Carlsbad, CA 92018-9898

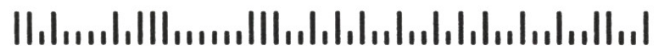
NECESSARY

IF MAILED

IN THE

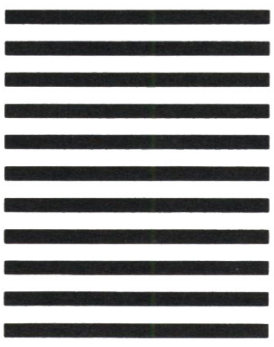

NO POSTAGE

NECESSARY

IF MAILED

IN THE UNITED STATES

\section{BUSINESS REPLY MAIL \\ FIRST CLASS PERMIT NO. 759 \\ CARLSBAD, CA}

POSTAGE WILL BE PAID BY ADDRESSEE

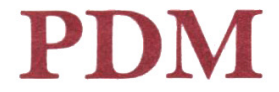

P.O. Box 2789

Carlsbad, CA 92018-9898

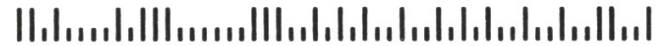

NO POSTAGE UNITED STATES

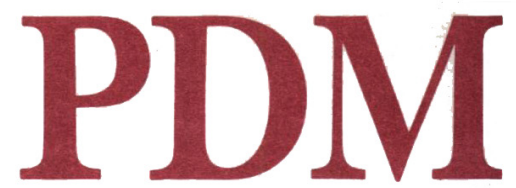

\section{PREHOSPITAL and DISASTER MEDICINE}

A quarterly peer-reviewed scientific journal for physicians, nurses, paramedics, instructors, administrators and researchers

The official journal of: The National Association of EMS Physicians

The World Association for Emergency and Disaster Medicine

In Association with the Acute Care Foundation and the National Association of State EMS Directors

\section{EMS INSIDER}

NECESSARY

IF MAILED

IN THE UNITED STATES

\section{BUSINESS REPLY MAIL FIRST CLASS PERMITNO.759 CARLSBAD, CA}

POSTAGE WILL BE PAID BY ADDRESSEE

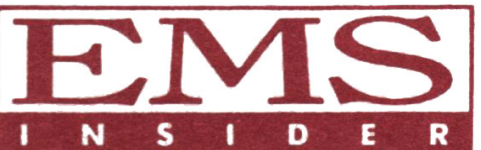

P.0. Box 2789

Carlsbad, CA 92018-9898

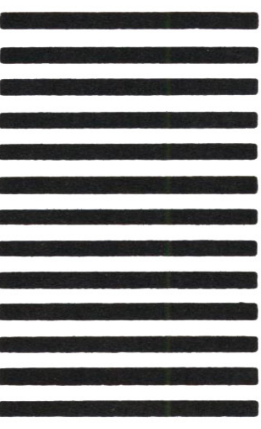

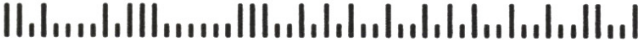


enough to adhere to a complicated protocol at 3:00 A.M. when the project obviously is important and relevant. The EMT will do his/her best if he/she feels the project will lead to better patient care. That is the prime motivation. Using a paramedic as co-author is not the answer. This may assure one person's cooperation, but it is not going to motivate others.

Finally, prehospital and emergent "informed" consent is a dilemma being discussed by many academic Emergency Medicine and EMS centers. Remember, informed consent is a new concept to most EMS personnel and will require even more extensive education and dissemination of information.

\section{How to Begin a Prehospital Research Project}

A) A preliminary meeting should be held with the Medical Director, EMS supervisors, and any nursing or administrative personnel involved in the project. This meeting also should be open to field personnel. The agenda should include:

1) Explain the goal of the research project and the need for answers to the research question, along with how these answers may apply to future patient care;

2) Allow authentic participation in implementation of these goals. Listen to your personnel and plan to use good suggestions. Don't just spoon-feed them with a protocol that you already have written;

3) Encourage questions and concerns in the field execution of the research protocol;

4) Explain how and why the research protocol will deviate from traditional practice;

5) Do not send out a typed protocol and expect compliance! EMTs are people, not robots, and will need explanations and motivation to perform at their best; and

6) Assess the probable impact of the research protocol on the EMT's workload and address this in your meetings and written communications. Make data collection forms as short and simple as possible (checklist). If the protocol and forms are complicated, reassure the per- sonnel of the length of the study, emphasizing the limited time involved.

B) Both for better patient care and better EMS-Emergency Department relations, notify and educate all receiving hospitals to reduce the stress on your EMS personnel. Blinded study drugs and unusual treatment protocols should be known to all receiving emergency physicians.

C) It is best to demonstrate physically new equipment or procedures, at least to the EMS supervisors, who can then demonstrate them to their field personnel. Larger systems can use videotape instruction to reach a larger audience.

D) On-scene assistance and supervision by research assistants, EMS supervisors, or the Medical Director is best in the early stages of complicated or controversial research projects.

E) It is very important to schedule follow-up meetings between the supervisors, research assistants, and the Medical Director to discuss progress, consistency, and problems. These meetings should be open to interested field personnel.

F) The Medical Director should spot-check the system occasionally by arriving on-scene unannounced to observe and further encourage the personnel.

G) Periodic bulletins or newsletters are an excellent form of communication and commendation to update field personnel on who is doing what. Include congratulations for successes and thanks for compliance. These can be posted prominently as encouragement. The research protocol can be outlined in each bulletin to remind and reinforce compliance.

The prehospital setting is an important venue for research. EMS personnel can and will collect excellent, reproducible data, but they must be motivated by a competent and credible leader. 


\section{The World of EMS is a Global Community.} Make it Your World

\author{
Join The World Association for \\ Emergency and Disaster Medicine
}

In the wake of the immensely successful and truly international meeting of the WAEDM in Hong Kong, and the less happy events of the Chinese and San Francisco earthquakes, it is becoming more important that all of us who share a feeling for and have some experience in emergency and disaster management should pool our resources for more energetic and fruitful response.

It was the feeling at both the Washington and Hong Kong meetings that one way of doing this would be to strengthen the already well established World Association for Emergency and Disaster Medicine. One expression of this has already materialized in our excellent new journal, Prehospital and Disaster Medicine, and the other expression has been in our increased membership. We look forward to this continued growth at our next international membership meeting in Montreal, Quebec, Canada in 1991.

It is a privilege to invite you to join what is undoubtably the prime organization in this field in the world.

Membership dues have been fixed at US\$75 per annum, which includes your subscription to our quarterly journal. Anyone involved in emergency administration, disaster planning, prehospital service, emergency nursing, EMS, and related subjects will be most welcome and will greatly benefit.

Kindly make your cheque or equivalent money order payable to:

The World Association for Emergency and Disaster Medicine

and send it to:

S. William A. Gunn, MD, MS, FRCSC

Secretary/Treasurer, WAEDM

"La Panatière"

1261 Bogis Bossey

Geneva, Switzerland

We look forward to having you among us and sharing with you our common endeavor against disasters.
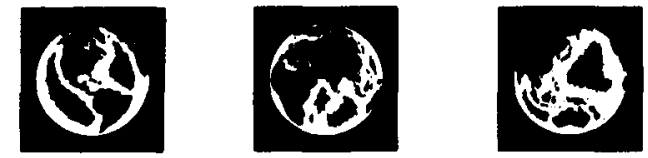

\section{National Association \\ of \\ EMS Physiclans}

\section{Membership Information}

\section{Full Mombership}

Full members shall be physicians who are actively engaged in the planning, supervision, teaching or clinical practice of prehospital emergency care. Full members shall enjoy all the privileges of the Association, including voting rights, committee membership, election of officers, conduction of business on behalf of the Association, and the right to advise and guide the Association in the conduct of its affairs.

$\$ 125.00 / y r$ *

\section{Organizational Mombership}

Each organizational member is allowed up to five (5) physician representatives. Organizational members shall enjoy the same privileges as full members but are permitted only one vote. Application must be accompanied by curriculum vitaes of all five (5) physicians.

$\$ 500.00 / y r . *$

\section{Rosident/Modical Student Membership}

Open to all residents/medical students interested in EMS. Application must be accompanied by a letter from residency program director or medical school dean verifying residency/student status and anticipated graduation date. Residents and medical students will enjoy all privileges of the Association as full members, however, only residents shall have the right to vote.

$\$ 50.00 / y r$ *

\section{Associate Membership}

Associate members shall be those persons who have demonstrated an interest in prehospital care and the aims of the Association through their writings, research, public pronouncements or activities. Associate members may be requested to sit on committees, to advise or to conduct research or investigations at the discretion of the Executive Committee. They shall have no right to vote, hold office or chair committees.

$\$ 50.00 / y r$ *

\section{For a membership application form write to:}

National Assoclation of EMS Physiclans EXECUTIVE AND NATIONAL RESOURCE CENTER 230 McKee Place, Suite 500 Pittsburgh, PA 15213 